\title{
Book Review \\ BIM Handbook: A Guide to Building Information Modeling for Owners, Managers, Designers, Engineers and Contractors \\ 2nd Edition
}

C Eastman, P Teicholtz, R Sacks and K Liston ISBN: 978-0-470-54137-1 (Hardcover) 648 pages, 2011, AUD \$105.00; NZD \$120.00, USD 85.00, GBP57.50, EUR 68.00

E-book version ISBN: 978-1-1180-2169-9 544 pages 2011 AUD \$84.99 / NZD \$99.99, USD 69.99, GBP 47.99, EUR 54.99

\section{"Extending BIM: A Review of the BIM Handbook"}

The BIM Handbook ( $2^{\text {nd }}$ Edition) provides very insightful understandings of the BIM concept, the associated approaches and processes, and the major enabling technologies. The book emphasizes more the business and organizational issues of BIM implementation than the detailed technical aspects of BIM technologies and tools. This makes the book distinct as Integrated Project Delivery and Lean Construction concepts are discussed together with BIM thus addressing the potential business and process-oriented issues in the actual BIM implementation. The book is well written, as a good starting reference for beginners and readers from both academia and industry. It gives a holistic picture of the fundamentals for understanding BIM. In summary, it is a very good book and I quite enjoyed it.

From the technical perspective, as classified by Autodesk, BIM tools can be applied in four aspects: representation, simulation, collaboration, and realization. The book covers well representation and simulation, as the majority of available BIM tools and adoptions as well as the best practice cases fall into these two functional categories.

It would have been desirable if it could also have covered the state-of-the-art advances in collaboration and simulation as well. For example, Groupware (computer-supported collaborative work) and Social Network Software (SNS) can potentially be integrated with existing BIM tool to better support BIM's collaborative capabilities. Other potential issues are how SNS tools such as SecondLife (Virtual Reality-based social tool), Facebook, Twitter, etc. can be integrated into BIM to support better multi-disciplinary synchronous and asynchronous collaboration and communication. It would be interesting to read about the current recognized $R \& D$ efforts in this direction.

Another of the four aspects is "Realization", which means how to bring BIM information onsite and bridge the gap from digital to physical world. Mobile computing, cloud computing (Cloud BIM) and Augmented Reality are promising technologies to enable this happen. Examples of recent industrial development include VELA, Bentley i-model running on iPad/iPhone, and so on. There has also been some exploratory lab-based research and development.

Chapter 8 discusses some future trends, and it would have been particularly inspiring if it could have covered the details of how to bring BIM onsite, which is very important if BIM is to fulfil its full potentials as originally promised. The integration of BIM with other advanced technologies such as Augmented Reality (AR), Virtual Reality (VR), mobile computing, Radio Frequency Identification Technologies (RFID), GPS, etc. is essential if this is to happen, and Figure 8-3 gives an example of a component-based simulation of an operating room, allowing the owners and designers to compare different equipment. There is some system that can project the real-scale BIM model into the real context space via Augmented Reality to compare how equipment and furniture fit into the space and determine whether or not the surrounding space is sufficient or not. 
The book discusses the processes and business well, although it could have been helpful to have a section concerning the cost-effectiveness or return on investment of adopting BIM, as this is always the most important question asked by industry when they first encounter BIM.

The governments in many countries are moving fast in developing their own national BIM standards and strategies. Some parts of the standards are similar, as regulators are learning from each other in the development of BIM standards, but there are also some distinct differences. It would be interesting to extract the main characteristics of BIM standards in representative countries and develop a comparison table as an overview.

The BIM handbook mainly focuses on the building industry. Many assets in oil and gas, mining and infrastructure can also embrace BIM and the practitioners in these industries are interested in BIM. It would have been very helpful and worthwhile to include some case studies in these specialized sectors into the book.

Prof Xiangyu Wang

Curtin University

Co-Director, Australasian Joint Research Centre for BIM 